\title{
Peer review clash in US agricultural research
}

The Carter administration is locked in a fierce struggle with members of Congress over the most effective way of financing basic research in the agricultural sciences.

The latest round took place last week, when the Senate agreed to restore to the Department of Agriculture's 1979 budget $\$ 30$ million which the administration had requested for a system of competitive research grants, but which had been rejected by the House of Representatives.

The administration's moves follow a number of reports which have appeared in recent years emphasising that quality of agricultural research can only be maintained by putting grant applications on to the conventional competitive basis used in other areas.

Opposition from members of Congress has reflected the fears of the numerous state colleges and research institutions which, under the Hatch Act of 1887, are at present allotted money for research purely on the basis of farm population and outputs.

Last year, the House cut $\$ 16.7$ million off an administration request for $\$ 26.7$ million for a competitive grants system; however, the full amount was restored by the Senate, and a compromise figure of $\$ 15$ million was eventually agreed upon.

The competitive grants programme is now under way, and following requests sent out by the Agriculture Department's Science and Education Department in February, over 1,000 research applications have been received for universities and colleges throughout the country-the total funding requested being over $\$ 200$ million.

Yet despite the popularity of the scheme in the scientific community, opposition remains high. And last month, particularly concerned at the administration's proposal to reduce

\section{Solar orbital satellite launched}

THE third and final satellite of the International Sun Earth Explorer, the US National Aeronautics and Space Administration's ISEE-C, was successfully launched on schedule from Cape Canaveral last Saturday. It is heading for an orbit around the Sun at a distance of 1.5 million $\mathrm{km}$ from Earth. In this orbit it will observe phenomena in interplanetary space, and particularly the solar wind.

The other two satellites in the ISEE programme, NASA's ISEE-A and ISEE-B built by the European Space Agency, were launched in tandem by NASA from a Delta 2914 rocket last October. They were both put into the same highly elliptical Earth orbit with
Hatch Act research "as part of a reorientation of research priorities" from $\$ 109$ million to $\$ 98$ million, the House not only voted to restore this cut, but also to delete the full $\$ 30 \mathrm{mil}$ lion which had been requested for competitive grants.

In giving reasons for the deletion, Representative Jamie Whitten, chairman of the house agriculture appropriations subcommittee, took a swipe at the peer-review system: "Congress must not allow itself to be placed in the position of being held accountable to the people for the research priorities established by a non-elected bureaucrat issuing grants to his fellow scientists."

And in order to rub the message in, the House included in the appropriations bill a detailed list of individuallydefined research grants, ranging from $\$ 10$ million for animal and health plant research, to $\$ 25,000$ for dried bean research.

The move provoked an angry reaction from the administration. Appearing before the Senate appropriations subcommittee, Agriculture Secretary

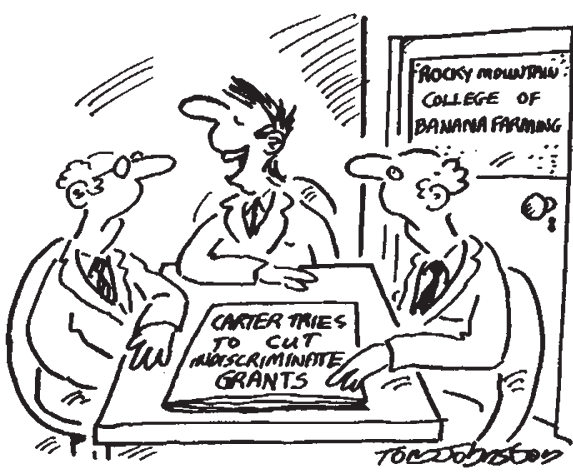

"Gentlemen, I think it's time we diversified into peanut research!"

closest and furthest points from the Earth of $280 \mathrm{~km}$ and $140,000 \mathrm{~km}$ respectively. Their task is to provide information on phenomena in the Earth's magnetoshpere. Their highly eliptical orbit was chosen so that the satellites will make as many crossings as possible of the boundary where the solar wind meets the magnetosphere. Observation of this boundary could provide information on the magnetic confinement of plasma and the interaction of ionised particles with the Earth's magnetic field.

ISEE-C has a dual function: to investigate interplanetary space and the solar wind undisturbed by the Earth and to act as a reference satellite for
Bob Bergland accused $\mathrm{Mr}$ Whitten of "seriously impairing" his right to run the department; and President Carter sent a personal letter to the subcommittee chairman, Senator Thomas Eagleton, asking him to restore the competitive grants scheme.

This was dutifully done by the subcommittee, and approved by the whole Senate last week, which also deleted the provisions added by the House for specific research topics.

During the debate, for example, the Senate accepted an amendment from Senator John Melcher of Montana adding \$20 million for animal health and disease research. Senator Melcher claimed that many states were underutilising the laboratory facilities and personnel existing in veterinary colleges and agricultural experiments stations; Senator Eagleton, in opposing the amendment, pointed out that the Department of Agriculture already plans to spend $\$ 47$ million on research in this area in 1979, and feels this to be "sufficient to address the priority needs" with no compelling reason to add more funds.

Responding to this and other amendments which would have added over $\$ 500$ million to the administration's request, the Senate subsequently approved a further amendment from Mr Eagleton cutting Hatch Act grants -which the Senate had previously increased from a requested $\$ 98$ million to $\$ 113.9$ million-by $\$ 9.5$ million to $\$ 104.4$ million. With honours now roughly even, the next round in the debate will take place in the conference between House of Senate. It is generally expected that about $\$ 15$ million-the same level as the current year-will be agreed for the competitive grants programme; but even this outcome will leave many far from satisfied.

David Dickson

ISEE-A and B. The satellite has been built by NASA but European scientists are participating in some experiments. Teams from Imperial College, London, Utrecht in the Netherlands and ESA's Space Science Department are cooperating on an investigation of protons in interplanetary space; a team from Garching, West Germany is doing a study of the composition of solar particles and a team from Meudon. France is conducting a study of magnetic field lines emanating from the Sun.

The three satellites have been planned to make major contributions to the International Magnetospheric Study running from 1976-79. 